\title{
ECE2016
}

Munich, Germany

\section{Importance of Levothyroxine Absorption Test in identifying malabsorption as cause of inadequate substitution for hypothyroidism}

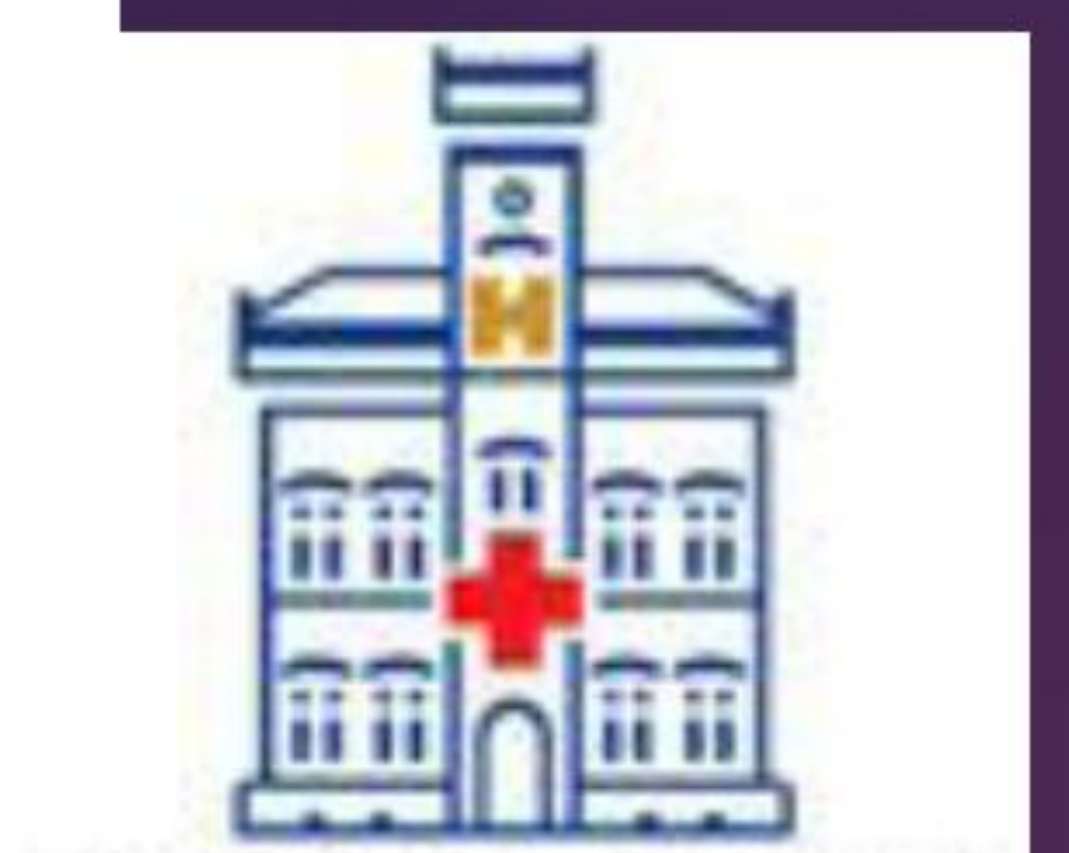

KLINICKO CENTAR SREWE

Lalic $T^{1}$, Ciric $\mathrm{J}^{1}, 2$, Beleslin $\mathrm{B}^{1}, 2$, Stojkovic $\mathrm{M}^{1}, 2$, Savic $\mathrm{S}^{1}$, Nisic $\mathrm{T}^{1}$, Barac $\mathrm{M}^{1}$, Stojanovic $\mathrm{M}^{1}, 2$, Zarkovic $M^{1,2}$

1.Clinic for Endocrinology, Diabetes and Metabolic disorders 2. School of Medicine, Belgrade University

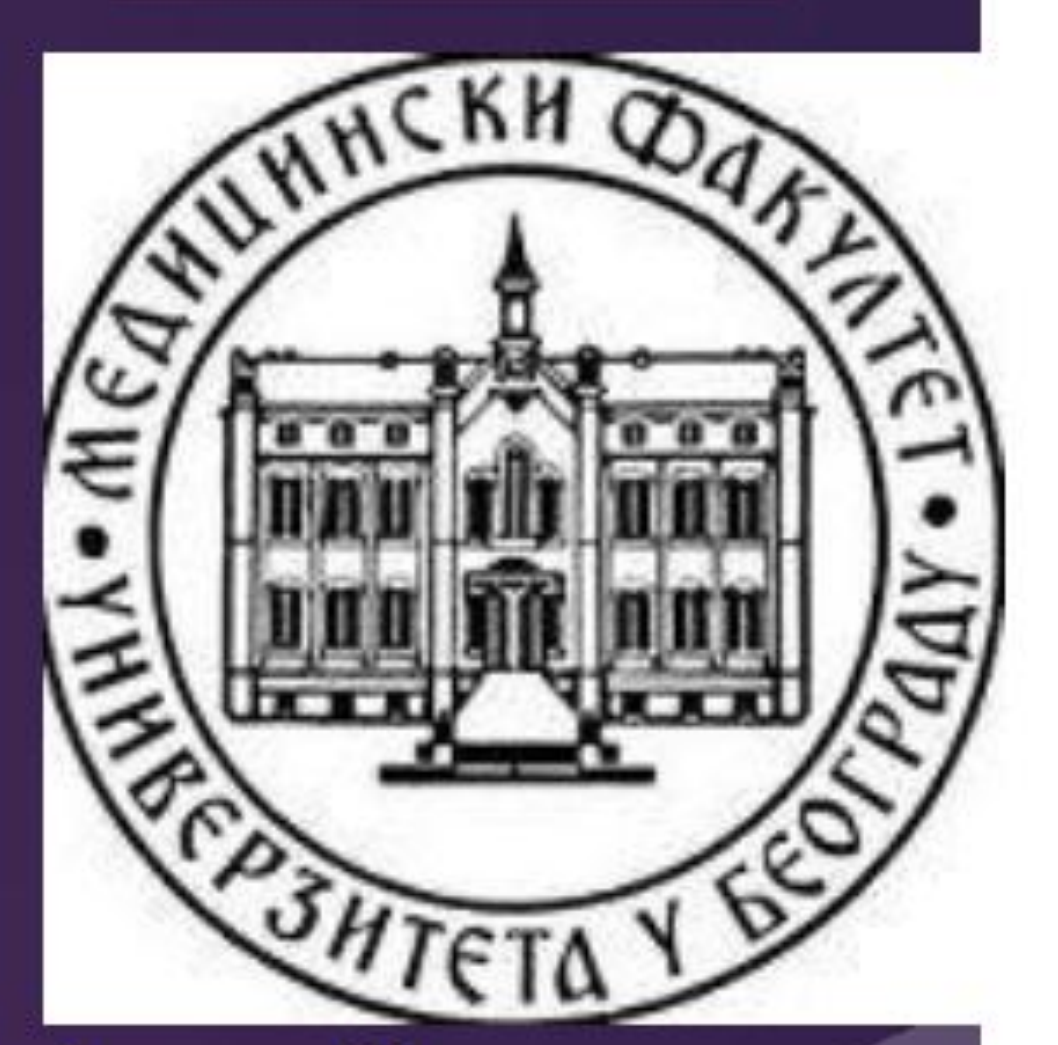

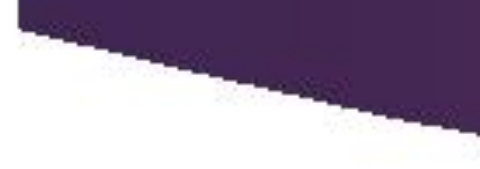

(1)

\section{- Introduction}

The most common cause for persistent elevation of TSH levels in hypothyroid patients treated with levothyroxine is poor compliance. The Levothyroxine Absorption Test (LAT) is usually confirmed this phenomenon called "pseudo-malabsorption".

\section{- Case report}

60 -year-old female, W $60 \mathrm{~kg}$, BMI $24.3 \mathrm{~kg} / \mathrm{m} 2$, presented with sleepiness, tiredness, fatigue and forgetfulness. Her skin was very dry and flaky. She had low tolerance of effort, poor appetite with weight oscillation around $2 \mathrm{~kg}$, constipation and sometimes heartburn.

Hypothyroid for ten years after radioiodine treatment of Graves' disease. Her TSH levels were higher than normal, TSH $20-70 \mathrm{mlU} / \mathrm{L}$, in spite of efforts to adjust the dose (different LT4 preparations). In last two years her daily LT4 dose was $900 \mu \mathrm{g}(15 \mu \mathrm{g} / \mathrm{kg}), 3 \times 300 \mathrm{mcg}$ then $500+400 \mathrm{mcg}$. She is also under treatment for depression, angina, hypertension, absolutely arrhythmias (with inadequate INR in last two months). Before testing TSH 33.6mlU/L, FT4 4.25 pmol/L.

Standard $(1000 \mu \mathrm{g})$ LAT was performed under supervision. TSH, T4 and FT4 were measured $2 \mathrm{~h}, 4 \mathrm{~h}$, $6 \mathrm{~h}$ and $24 \mathrm{~h}$ upon LT4 administration. Baseline values were TSH $26.92 \mathrm{mlU} / \mathrm{L} ; \quad \mathrm{FT} 4 \quad 4.4 \mathrm{pmol} / \mathrm{L} ; \mathrm{T} 4$ 41.5pmol/L. Cmax T4 88.6pmol/L was in 120'. The end point values were TSH $29.37 \mathrm{mIU} / \mathrm{L}$; FT4 $7.2 \mathrm{pmol} / \mathrm{L}$; T4 $61.9 \mathrm{pmol} / \mathrm{L}$. The lack of TSH fall and slight increase in T4 and FT4, significantly below expected AUC, pointed an inadequate absorption.

\section{$>$ Conclusion}

LAT is useful for identifying much rare malabsorption, so the adequate treatment could lead to proper substitution and avoidance of no rationale increase of levothyroxine dose.

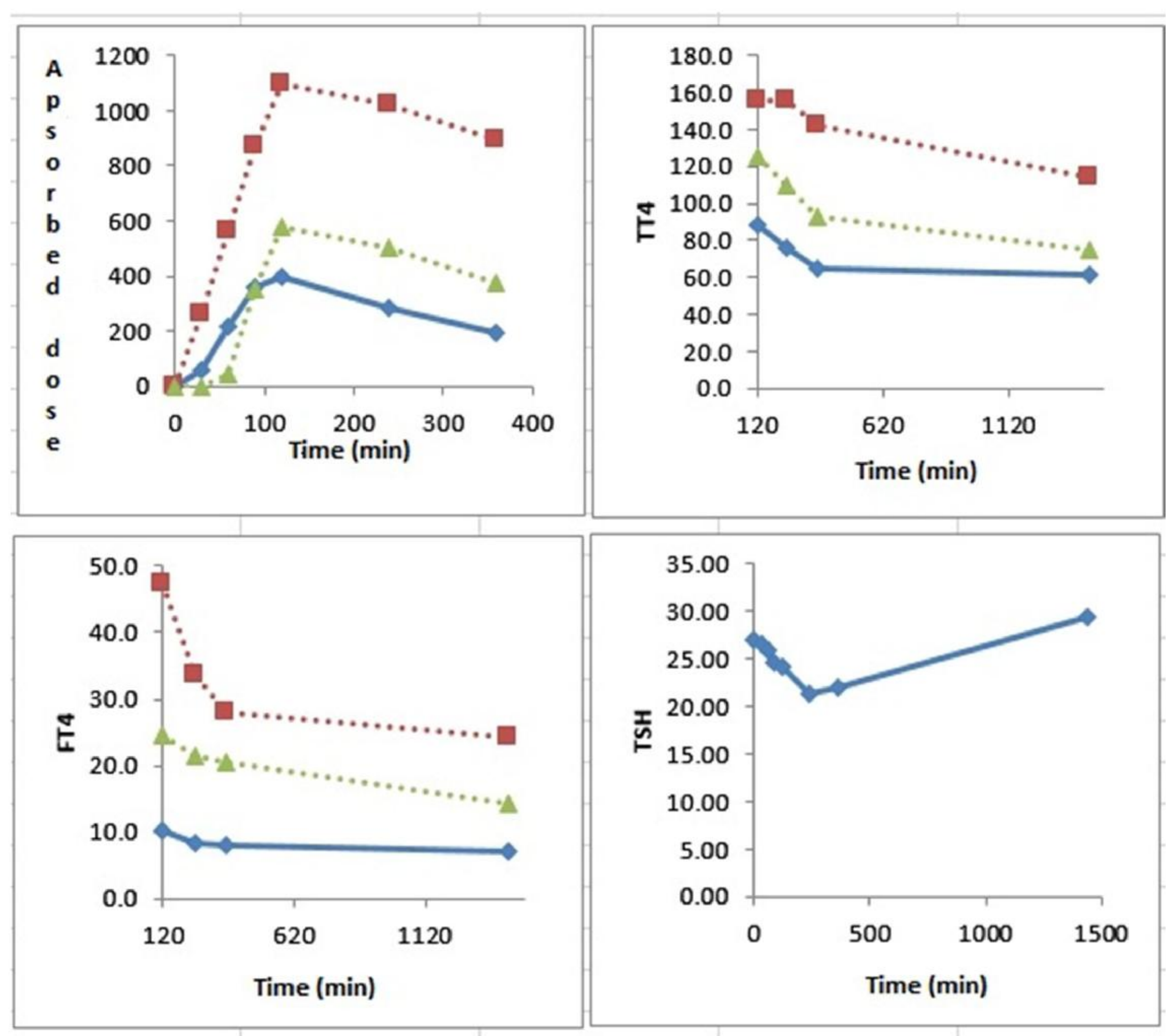

After testing, it was started with $300 \mu \mathrm{g}$ LT4 oral suspension. The presence of fat in the stool and positive antiparietal antibodies increased suspicion to malabsorptiv syndrome. EGDS was performed and $\mathrm{PH}$ finding confirmed $\boldsymbol{H}$.pylori positive chronic atrophic gastritis with micro focal intestinal metaplasia without morphological elements for GSE. Eradication treatment and IPP were introduced. After four weeks her thyroid hormones were TSH $1.63 \mathrm{mlU} / \mathrm{L}$; FT4 $26.6 \mathrm{pmol} / \mathrm{L}$, FT3 $3.87 \mathrm{pmol} / \mathrm{L}$.

EP-330 Clinical case reports Thyroid/Others $1^{\text {st }}$ Autor Lalic T. 